\title{
ANALISIS RESPON PENAWARAN KOMODITI JAGUNG DI KABUPATEN MUARO JAMBI
}

\author{
Edison dan Ratnawaty Siata \\ Fakultas Pertanian Universitas Jambi \\ e-mail: ediedison950@yahoo.co.id
}

\begin{abstract}
S
Penelitian ini bertujuan (1) menilai faktor produksi dan pengaruhnya pada produksi jagung, dan meng-investigasi kemampuan level input, seperti luas areal dan lainnya untuk menjelaskan respon produksi; dan (2). menilai respon penawaran petani terhadap harga input, penerimaan harapan kotor, program pemerintah dalam usahatani, risiko dari variabel yang berhubungan, dan variabel exogenous lainnya. Dalam upaya untuk mendapatkan model respon penawaran jagung pada lahan kering di Kabupaten Muaro Jambi. Penelitian ini dilaksanakan dari Mei 2017 hingga November 2017 di Kabupaten Muaro Jambi. Pelaksanaan penelitian digunakan data primer dan sekunder. Data yang digunakan dalam penelitian ini adalah data Musim Tanam tahun 2016 untuk Kabupaten Muaro Jambi dan Kecamatan Kumpeh dipilih secara sengaja (purposive) karena daerah ini merupakan sentra produksi jagung di Kabupaten Muaro Jambi. Metode analisis dalam aplikasinya dipilah berdasarkan tujuan penelitian yakni Model Empiris Fungsi Respon Penawaran. Dari penelitian didapatkan hasil Model respon penawaran jagung sangat dipengaruhi oleh banyak faktor. Diantaranya faktor internal maupun eketernal seperti harga padi, penggunaan input, dan musim, yang cukup relevan dimana produksi jagung meningkat karena harga padi meningkat. Ditambahkan pula bahwa produksi jagung menurun bila variabel input yang digunakan tidak sesuai dengan ketentuan. Seperti yang diharapkan ditemukan juga bahwa luas panen juga penentu tanaman yang signifikan. Selanjutnya ditemukan bahwa produksi jagung meningkat pada musim hujan. Temuan ini konsisten dengan fakta bahwa ketersediaan air adalah faktor penting untuk tanaman jagung. Analisis menerangkan juga bahwa petani jagung lahan kering didaerah penelitian respon terhadap perubahan penggunaan input yang efisien. Penawaran output adalah respon terhadap produksi jagung. Pada permintaan input, banyak sensitif terhadap penggunaan tenaga kerja, tenaga pemeliharaan/ pemanenan. Elastisitas produksi yang diperoleh melengkapi bagian dari data base yang diperlukan intuk mengevaluasi implikasi kebijaksanaan penggunaan input alternatif dari persediaan jagung dan permintaan input.
\end{abstract}

Kata kunci : model respon penawaran, komoditi jagung, produksi, dan fungsi produksi

\section{PENDAHULUAN}

Kabupaten Muaro Jambi merupakan daerah sentra produksi jagung terbesar di Provinsi Jambi, dibandingkan dengan daerah atau kabupaten lainnya. Hal ini dikarenakan pesatnya perkembangan usaha peternakan di Kabupaten Muaro Jambi, yang mendorong tingginya permintaan akan kebutuhan pakan ternak yang mendorong tingginya permintaan akan kebutuhan pakan ternak yang bersumber dari tanaman jagung. Untuk melihat sebaran luas panen, produksi dan produktivitasnya lebih jelas dapat dilihat pada Tabel 1 berikut. 
Tabel 1. Luas Panen, Produksi dan Produktivitas Tanaman Jagung menurut Kabupaten/Kota di Provinsi Jambi Tahun 2015

\begin{tabular}{clccc}
\hline No & Kabupaten/Kota & $\begin{array}{c}\text { Luas Panen } \\
\text { (ha) }\end{array}$ & $\begin{array}{c}\text { Produksi } \\
\text { (ton) }\end{array}$ & $\begin{array}{c}\text { Produktivitas } \\
\text { (kw/ha) }\end{array}$ \\
\hline 1. & Kerinci & 1.821 & 12.036 & 66,10 \\
2. & Merangin & 338 & 1.570 & 46,46 \\
3. & Sarolangun & 134 & 580 & 43,27 \\
4. & Batanghari & 59 & 272 & 46,15 \\
5. & Muaro Jambi & $2 . / 755$ & 15.300 & 55,54 \\
6 & Tanjab Timur & 799 & 4.000 & 50.06 \\
7 & Tanjab Barat & 746 & 3.208 & 43,00 \\
8 & Tebo & 105 & 486 & 46,18 \\
9 & Bungo & 1.041 & 5.530 & 53,12 \\
10 & Kota Jambi & 70 & 306 & 43,74 \\
11 & Sungai Penuh & 69 & 329 & 47,72 \\
\hline
\end{tabular}

Sumber : Jambi Dalam Angka, 2016

Berdasarkan Tabel 1 dapat dilihat bahwa Kabupaten Muaro Jambi adalah kabupaten yang memiliki luas panen dan produksi jagung yang tertinggi dibandingkan dengan kabupaten lainnya yang ada di Provinsi Jambi. dengan luas panen mencapai 2.755 ha atau 34,7\% dari total luas panen jagung di Provinsi Jambi. Sedangkan produksinya mencapai 15.300 ton atau 35\% dari total produksi jagung yang ada di Provinsi Jambi. Hal ini menunjukkan bahwa Kabupaten Muaro Jambi memiliki potensi yang besar bagi perkembangan usahatani jagung.

Kabupaten Muaro Jambi memiliki beberapa kecamatan yang seluruh wilayahnya merupakan daerah penghasil jagung. Berdasarkan Tabel 2 berikut, Kecamatan Kumpeh merupakan sentra produksi tanaman jagung dan salah satu daerah yang memiliki potensi terbesar sebagai daerah penghasil jagung di Kabupaten Muaro Jambi dibandingkan kecamatan lainnya.

Tabel 2. Luas Panen, Produksi, Produktivitas Jagung Menurut Kecamatan di Kabupaten Muaro Jambi 2015

\begin{tabular}{llccc}
\hline No & Kecamatan & $\begin{array}{r}\text { Luas } \begin{array}{c}\text { Panen } \\
\text { (ha) }\end{array} \\
\begin{array}{r}\text { Produksi } \\
\text { (ton) }\end{array}\end{array}$ & $\begin{array}{c}\text { Produktivitas } \\
\text { (ton,ha) }\end{array}$ \\
\hline 1 & Mestong & 151 & 625 & 4,14 \\
2 & Sungai Bahar & 174 & 690 & 3,96 \\
3 & Kumpeh Ulu & 834 & 3.354 & 4,02 \\
4 & Kumpeh & 6.342 & 25.680 & 4,05 \\
5 & Maro Sebo & 803 & 3.202 & 3,99 \\
6 & Jambi Luar Kota & 386 & 1.549 & 4,01 \\
7 & Sekernan & 162 & 674 & 4,16 \\
8 & Sungai Gelam & 384 & 1.475 & 3,84 \\
\hline & Jumlah & 9.236 & 37.249 & 4,01 \\
\hline
\end{tabular}

Sumber: Badan Pusat Statistik Provinsi Jambi, 2016

Perkembangan produksi jagung sementara efektif untuk beberapa tahun terakhir, mungkin relatif sulit diulangi pada masa mendatang. Data produksi yang disarikan dari program pembangunan tanaman jagung di Provinsi Jambi menurut era Orde Baru (1986-1987) dan reformasi (1989-2011) dari tiga tipologi lahan jagung yang ada. Beragamnya tingkat produksi akan mencerminkan adanya faktor ketidakpastian dan risiko dalam berusahatani jagung. Disamping itu karena terjadinya krisis ekonomi dan kesulitan keuangan yang mengakibatkan subsidi input untuk kegiatan ini berkurang (Edison, 2011). Dengan kondisi 
seperti ini, para ahli bidang kebijakan pertanian tertarik dalam mengamati respon penawaran dan permintaan input pada petani jagung. Estimasi respon penawaran seperti perubahan penggunaan input telah dilaporkan dalam beberapa kajian (Guyomard, et al. 2003). Namun sangat sedikit yang meneliti respon penawaran dan permintaan input dalam kaitannya dengan perubahan harga.

Dengan melihat pada tujuan pembangunan pertanian yakni untuk dapat meningkatkan kesejahteraan petani, penelitian ini mencoba menganalisa masalah-masalah tersebut diatas terutama untuk mengetahui sejauh mana upaya-upaya pengembangan komoditas jagung yang telah dilakukan dalam rangka menemukan model respon penawaran komoditi jagung pada lahan kering di Kabupaten Muaro Jambi.

\section{TINJAUAN PUSTAKA}

Bukhshoodeh dan Shajari (2006) menyatakan bahwa perubahan harga relatif pupuk akan mengakibatkan produsen merubah varietas bibit dengan pupuk yang berbeda responnya dalam rangka memaksimumkan keuntungan dengan memperhatikan fungsi produksi metarespon. Fungsi Meta-Respon (FMR) yang dikembangkan Pitt (1999) menerangkan proses keputusan petani dibawah ketidakpastian. FMR didefinisikan sebagai envelope fungsi produksi tidak langsung yang dikaitkan dengan setiap fungsi teknologi alternatif. Pendekatan ini dikembangkan untuk menyelesaikan model fungsi respon produksi aslinya yang dikenalkan oleh Lau dan Yotopoulus (1972). Namun, asumsi keuntungan yang memaksimumkan tujuan telah dikritik secara luas oleh Dillon dan Anderson ( $\mathrm{Lu}$ et al., 2006). Model lain dari pendekatan fungsi keuntungan termasuk (a) model statis, (b) keuntungan aktual (dimana positif) digunakan sebagai proxy untuk keuntungan harapan, dan (c) estimasi aktual dari fungsi keuntungan juga berkaitan dengan perbedaan petani yang menghadapi input yang berbeda dan harga produk. FMR boleh digunakan untuk masalah ini (Pitt, 1999). Namun beberapa pendekatan dapat dimodifikasi untuk memasukkan expected utility.

Kikuchi dan Hayami (1998) menyatakan bahwa perubahan harga relatif dari pupuk akan mengakibatkan percepatan perubahan penggunaan bibit unggul dengan perbedaan intensifikasi pupuk sehingga dapat memaksimumkan keuntungan dengan mempertimbangkan fungsi meta produksi. Fungsi meta produksi adalah berbentuk envelop yang terdiri dari permukaan produksi dari seluruh input yang digunakan seperti bibit unggul, sistim irigasi dan teknik bercocok tanam seperti terlihat pada Gambar 1 berikut.

Pendekatan FMR mengasumsikan bahwa utilitas petani tergantung pada maksimum fungsi keuntungan harapan dengan kendala harga output, harga input, dan sekumpulan input variabel. Jadi fungsi ini didefinisikan sebagai berikut :

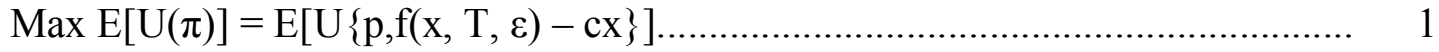

dimana :

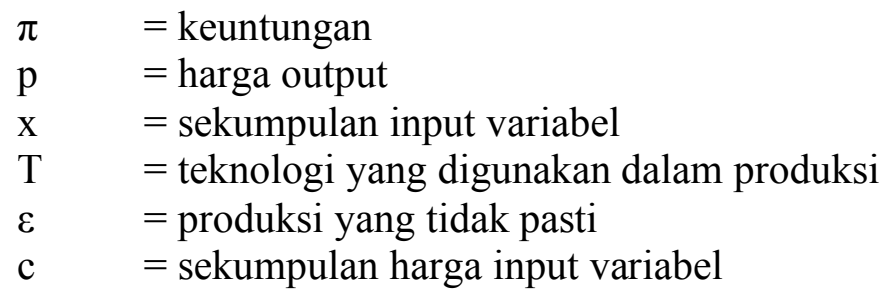




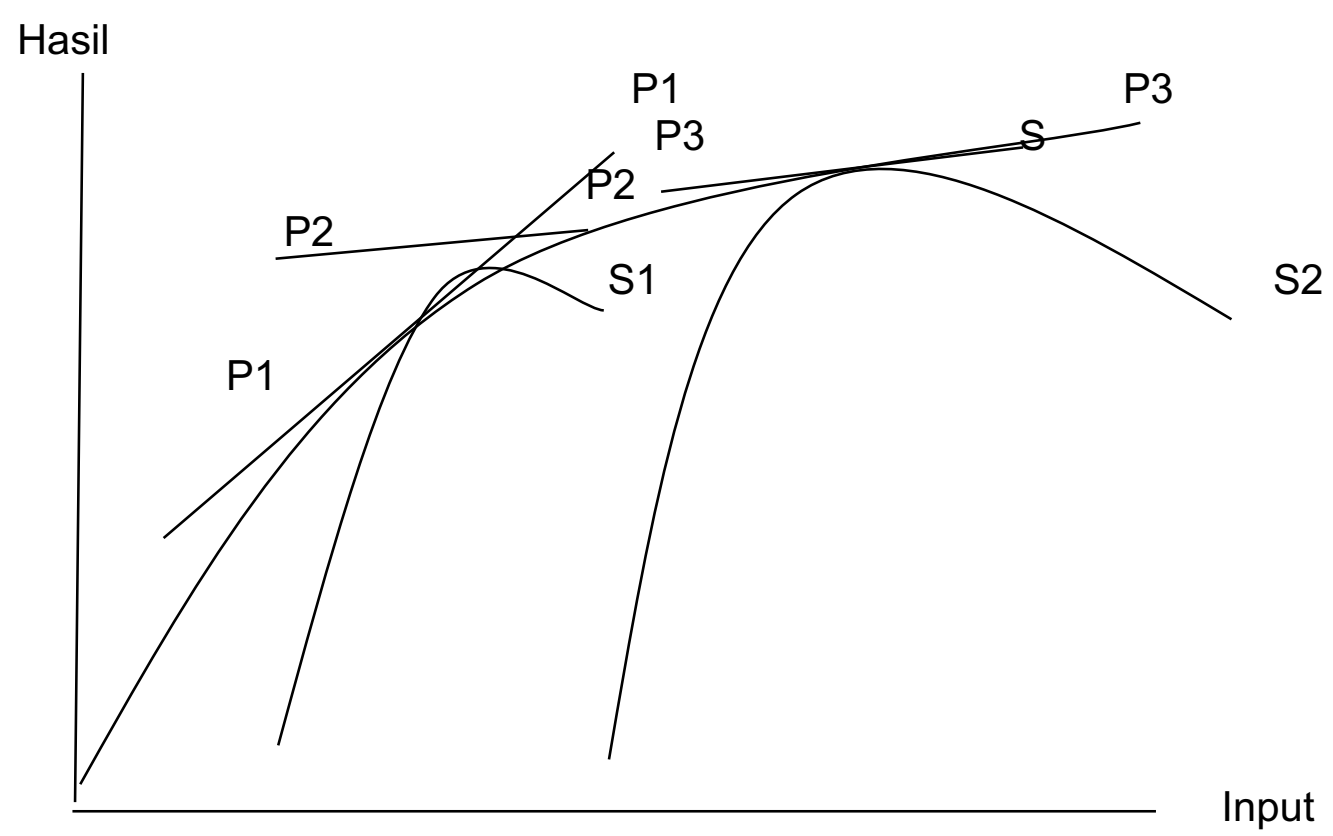

Gambar 1. Aplikasi Input Optimal Sepanjang Permukaan Meta-Respon

Jika asumsi $\mathrm{f}^{\prime}()>$.0 dan $\mathrm{f}^{\prime}()<$.0 digunakan, dan jika risiko masuk dalam bentuk tambahan (Pope dan Kramer, 1999), kumpulan input variabel $X^{*}$ yang memaksimumkan expected utility of profit adalah :

$$
\mathrm{X}^{*}=\mathrm{d}^{*}(\mathrm{P}, \mathrm{C}, \mathrm{T}, \theta, \varepsilon)
$$

dimana :

$\theta \quad=$ momen produksi

Bila persamaan (2) disubstitusikan ke (1) indirect expected utility of profit dapat diturunkan sebagai berikut :

$\mathrm{E}\left[\mathrm{U}\left(\pi^{*}\right)\right]=\mathrm{E}\left[\mathrm{v}^{*}(\mathrm{P}, \mathrm{C}, \mathrm{T}, \theta, \varepsilon)\right]$

Secara umum, diasumsikan bahwa petani membentuk variabel harapan diluar kendalinya jadi pilihan input terjadi ex-ante terhadap realisasi output, akhirnya fungsi penawaran produk adalah fungsi supply ex-post, karena saat pertama-tama produksi direalisasikan, pilihan petaninya adalah hanya untuk menjual pada harga pasar lokal (Aiginger, 2002).

Analisis ekonomi meningkatkan konfrontasi masalah yang diungkapkan melalui perubahan struktur pada spesifikasi dan estimasi model ekonomi. Dalam analisis supply pertanian, perubahan struktur yang penting telah merefleksikan dampak program pemerintah pada usahatani yang berusaha untuk mengendalikan produksi. Akibatnya integrasi perubahan program usahatani dalam model respon penawaran tanaman telah mendapat perhatian pada penelitian terdahulu (Houck dan Ryan, 2003).

Pada dua dekade, respon penawaran luas areal jagung telah mendapat perhatian bagi pembuat kebijakan. Hal ini karena pemerintah ingin mengulas keefektifan program komoditi usahatani. Penekanan khusus telah diungkapkan untuk ukuran empiris dan analisis pengaruh dan dampak program pemerintah dalam usahatani. Begitu juga dengan program program dukungan harga dan subsidi input.

Sehingga dengan memperhatikan permasalahan diatas dalam mempertimbangkan program pengembangan produksi, dianggap perlu mengevaluasi lebih lanjut permasalahan diatas dalam rangka untuk menemukan model pengembangan produksi jagung yang baik. 


\section{METODE PENELITIAN}

Penelitian dilakukan di Kabupaten Muaro Jambi karena Kabupaten Muaro Jambi merupakan salah satu sentra produksi jagung di Provinsi Jambi. Penentuan lokasi dilakukan dengan sengaja (purposive) dengan pertimbangan bahwa lokasi tersebut merupakan sentra produksi jagung di Provinsi Jambi yang dapat mewakili ketiga agroekosistem yakni lahan dataran rendah, dataran sedang dan dataran tinggi. Penelitian dilaksanakan pada Mei 2017 sampai November 2017.

Data yang dikumpulkan dalam penelitian ini meliputi data primer dan data sekunder. Data primer diperoleh dari hasil wawancara langsung dengan petani yang datanya diambil dari sejumlah produksi musim tanam terakhir tahun 2017, sedang data sekunder diperoleh dari studi kepustakaan dengan mengambil data dari buku, jurnal maupun tulisan ilmiah yang sudah dibukukan dan dipublikasikan.

Penelitian ini dilaksanakan di Kecamatan Kumpeh Kabupaten Muaro Jambi. Dalam pelaksanaan penelitian ini akan dipilih dua desa secara sengaja (purposive) dengan pertimbangan desa tersebut memiliki luas panen dan produksi jagung terbesar, yaitu Kelurahan/Mekarsari dan Desa Pulau Mentaro. Dari sumber Badan Penyuluhan Pertanian di Kecamatan Kumpeh diperoleh bahwa jumlah kelompok tani yang ada di Desa Mekarsari yang mengusahakan jagung adalah sebanyak 10 kelompok tani, dari 10 kelompok tani terdapat 165 orang, sedangkan kelompok tani yang ada di desa Pulau Mentaro adalah sebanyak 5 kelompok tani dengan jumlah anggota sebanyak 142 orang. Jadi, jumlah populasi di desa penelitian keseluruhan adalah 307 orang. Dengan menggunakan formula slovin diambil sampel sebanyak 84 yang diambil dengan menggunakan stratified random sampling.

Dari hasil perhitungan diatas maka diperoleh jumlah sampel petani dari dua Desa yaitu di Desa Mekarsari jumlah sampel petani sebanyak 43 sampel dan di Desa Pulau Mentaro jumlah sampel petani sebanyak 41 sampel, selanjutnya jumlah petani yang akan dijadikan sebagai responden dari sepuluh kelompok tani di Desa Mekarsari dan lima kelompok tani di Desa Pulau Mentaro tersebut diambil melalui rumus metode alokasi sampel proporsional.

Metode analisis ini dalam aplikasinya dipilah berdasarkan tujuan penelitian yakni Model Empiris Fungsi Meta-Profit; Dalam penelitian ini, fungsi translog untuk model empiris dari fungsi keuntungan digunakan. Dalam model keuntungan, pada dasarnya variabel penerang yang sama seperti fungsi produksi digunakan, kecuali mereka diungkapkan dalam basis perhektar. Model empiris dari fungsi keuntungan dapat ditulis seperti bentuk logaritma dari fungsi Cobb-Douglas berikut ini:

Normalisasi fungsi keuntungan yang digunakan pada kajian ini untuk menentukan respon penawaran petani jagung diekspresikan sebagai :

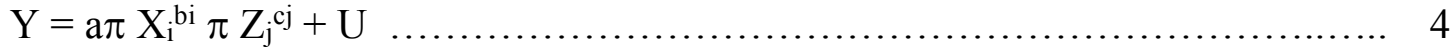

Penormalan terbatas dari fungsi keuntungan, diturunkan dari fungsi produksi (1), dijelaskan oleh Lau dan Yotopoulus (1979) :

$\operatorname{Ln} \pi^{*}=\ln \alpha+\Sigma \beta_{\mathrm{I}} \ln \mathrm{P}_{\mathrm{i}}+\Sigma \tau_{\mathrm{j}} \ln \mathrm{Z}_{\mathrm{j}}+\mathrm{U}$

dimana :

$\pi^{*} \quad$ : profit terbatas, yang dinormalkan $(\mathrm{Rp})$

$\mathrm{P}_{1} \quad$ : harga pupuk/ yang dinormalkan (Rp)

$\mathrm{P}_{2} \quad$ : harga pestisida/ yang dinormalkan $(\mathrm{Rp})$

$\mathrm{P}_{3} \quad$ : upah riel/pemeliharaan (Rp)

$\mathrm{P}_{4} \quad$ : upah $\mathrm{riel} /$ pemanenan $(\mathrm{Rp})$

$\mathrm{Z}_{1} \quad$ : luas lahan (Ha)

$\mathrm{Z}_{2} \quad$ : modal yang digunakan (Rp.)

U : kesalahan 
$\alpha, \beta, \tau, \Sigma=$ parameter estimasi

Estimasi fungsi penawaran dengan sampel pilihan diuji dengan metode dua tahap (twostage method). Nilai Chi-kuadrat digunakan untuk menguji hipotesis. Estimasi parameter dari fungsi penawaran diperoleh dari prosedur dua tahap ini adalah konsisten (Judge, 2004). Hal ini dikenal bahwa parameter estimasi tidak mengukur langsung pengaruh perubahan satu unit variabel penerang untuk mengubah tingkat keuntungan dari produksi tanaman atau varietas.

Untuk mendapatkan level optimal variabel input, Shephard-Hotelling lemma konsep yang digunakan pada kasus fungsi keuntungan terbatas Cobb-Douglas sebagai berikut:

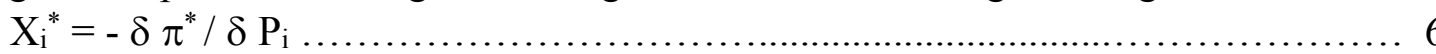

Persamaan (3) disusun kembali dan diestimasi secara empiris seperti :

$\left(\mathrm{X}_{\mathrm{i}}^{*} \mathrm{P}_{\mathrm{i}}\right) / \pi^{*}=\beta_{\mathrm{I}}+\mathrm{V}_{\mathrm{t}}$

dimana

$\mathrm{X}_{\mathrm{i}}^{*}=$ kuantitas variabel input

$\mathrm{V}_{\mathrm{t}}=$ kesalahan (error)

Karena fungsi produksi diasumsikan dalam bentuk Cobb-Douglas, solusi simultan persamaan (7) dan fungsi keuntungan (4) melengkapi estimasi elastisitas faktor permintaan, Zellner's seemingly unrelated regretion method, melengkapi efisiensi parameter $\alpha, \beta, \tau, \Sigma$ (Judge, 2004).

Model ini diestimasi dengan Ordinary Least Squares untuk mengestimasi koefisien, $\mathrm{R}^{2}$, nilai-t, dan nilai Durbin Watson.

\section{HASIL DAN PEMBAHASAN}

\subsection{Estimasi Fungsi Meta-Production}

Studi ini meneliti respon penawaran komoditi jagung yang ada dalam fungsi produksi. Parameter dari fungsi produksi yang diharapkan dengan menggunakan ordinary least squares. Dalam rangka untuk menguji signifikansi dari setiap parameter, hipotesis nol dapat dinyatakan sebagai $\mathrm{H}_{0}: \beta_{1}=\beta_{2}=\ldots \ldots=\beta_{\mathrm{n}}=0$

Hasil estimasi parameter produksi tanaman optimal menunjukkan bahwa hipotesis $\beta_{1}=$ $\beta_{2}=\ldots \ldots=\beta_{\mathrm{n}}=0$ dapat ditolak. Perkiraan elastisitas fungsi produksi untuk jagung yang tercantum dalam Tabel 3, R-squared yang disesuaikan untuk estimasi OLS adalah 0,711, dan F-statistik $(4,83)$ adalah 11,75 , yang secara signifikan lebih besar daripada F-tabel $(4,83, \alpha=$ $0,01)=3,55$. Ini berarti bahwa paling tidak salah satu dari parameter tidak sama dengan nol. Dari Tabel 3. Juga dapat dilihat bahwa parameter dari beberapa variabel penjelas secara signifikan berbeda dari nol.

\subsection{Memaksimumkan Produksi}

Kondisi penting untuk menurunkan fungsi produksi yang digunakan adalah bahwa petani memaksimumkan short term produksi. Keabsahan asumsi ini dapat diuji secara langsung dengan mengujinya apakah parameter $\beta$ diturunkan dari persamaan faktor permintaan secara bersamaan (Keeney dan Hertel. 2008). Jika parameter $\beta$ diturunkan dari dua persamaan ini tidak berbeda nyata, lalu petani sampel rata-ratanya memaksimumkan short term produksi, dengan tersedianya teknologi dan sumber daya. Karena sangat layak untuk mengestimasi secara simultan persamaan produksi dan faktor permintaan untuk menghindari masalah bias dari persamaan simultan, Bakhshoodeh dan Shajari. (2006), menggunakan statistik P untuk

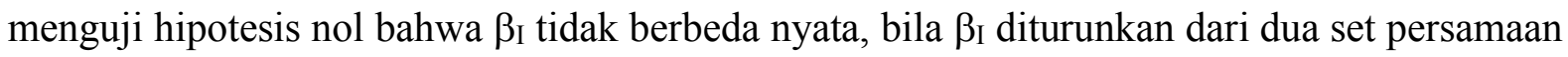
yang terpisah dan tergabung. 
Lagrange multipliers tidak berbeda nyata dari nol, begitu pula dengan uji $\mathrm{X}^{2}$ (Tabel 3). Jadi hipotesa bahwa petani jagung lahan kering didaerah penelitian memaksimumkan produksi tidak dapat ditolak.

Tabel 3. Uji Restriksi pada Parameter $\beta$ Fungsi Produksi dan Fungsi Faktor Permintaan

\begin{tabular}{lllll}
\hline Restriksi & \multicolumn{2}{l}{ Lagrange $(\lambda)$} & Multiplier $(\mathrm{t})$ & $\mathrm{X}^{2}$ Uji Statistik \\
\hline Pupuk & 0,428 & $(1,883)$ & 0,713 & \\
Pestisida & 0,399 & $(2,085)$ & 0,118 & 6,097 \\
Pemeliharaan & 0,516 & $(3.008)$ & 0,429 & \\
Pemanenan & 1,462 & $(2.328)$ & 1,683 & \\
\hline
\end{tabular}

\subsection{Elastisitas Penawaran Output dan Permintaan Input}

Parameter estimasi dari fungsi produksi dan elastisitas faktor permintaan dilihat pada Tabel 4. Koefisien adalah benar dalam tandanya, selain tenaga pemeliharaan, mereka lebih besar dari nol.

Tabel 4. Estimasi Gabungan yang Menormalkan Fungsi Produksi dan Elastisitas Faktor Permintaan

\begin{tabular}{|c|c|c|}
\hline Variabel & Estimasi Restriksi & Elastisitas Faktor Demand \\
\hline Konstanta & 947,094 & \\
\hline Input Pupuk & $-0,503 * *(0,502)$ & $-0,279 * * \quad(0,158)$ \\
\hline Input Pestisida & $-0,327 * *(0,429)$ & $-0,214 * * \quad(0,129)$ \\
\hline Tenaga Pemeliharaan & $-0,319 \quad(0,009)$ & $(0,048)$ \\
\hline Tenaga Pemanenan & $-0,472 * *(0,411)$ & $-0,324 * * \quad(0,192)$ \\
\hline Luas Lahan & $0,441^{*} \quad(0,217)$ & \\
\hline Modal & $0,403 * \quad(0,198)$ & \\
\hline
\end{tabular}

Elastisitas penawaran untuk jagung lahan kering dengan mempertimbangkan input yang digunakan (diestimasi sebagai $\Sigma \beta_{\mathrm{I}}$ ) diperkirakan mendekati satu $(0,959)$. Implikasinya, petani sampel respon terhadap perubahan input jagung. Untuk maksud perencanaan, $1 \%$ input jagung berubah, ceteris paribus, akan membawa perubahan yang serupa $(0,959 \%)$ penawaran jagung dari Kabupaten Muaro Jambi.

Estimasi menerangkan bahwa 10\% tenaga kerja meningkat, akan menyebabkan sekitar 7,91\% penawaran jagung meningkat terdiri dari 3,19\% peningkatan karena pemeliharaan tanaman, dan 4,72\% peningkatan karena peningkatan tenaga kerja yang digunakan untuk pemanenan. Jika tenaga kerja yang digunakan meningkat, digunakan untuk pemanenan. Jika tenaga kerja meningkat, penyesuaian dalam tenaga kerja yang digunakan untuk pemeliharaan mungkin bagian dari meningkatnya penggunaan pemupukan.

Estimasi elastisitas faktor permintaan untuk pupuk adalah 0,503, ini berarti $10 \%$ input pupuk naik, menyebabkan 5,03\% penggunaan pupuk meningkat dalam jangka pendek. Jadi dengan fungsi produksi yang ada, akan meningkatkan produksi dengan proporsi yang sama. Elastisitas output dengan mempertimbangkan input lahan melebihi sementara dengan modal. Jadi didalam ukuran usahatani akan berdampak pada produksi bila dibandingkan dengan peningkatan intensitas modal usahatani. 


\subsection{Elastisitas Produksi}

Melalui konsep duality, terdapat korespondensi antara produksi dan fungsi produksi. Hasilnya elastisitas produksi implisit dapat diturunkan dari fungsi produksi. Elastisitas produksi $\left(b_{i}{ }^{\prime}\right.$ dan $c_{j}{ }^{\prime}$ ) diturunkan dari parameter fungsi produksi sebagai berikut :

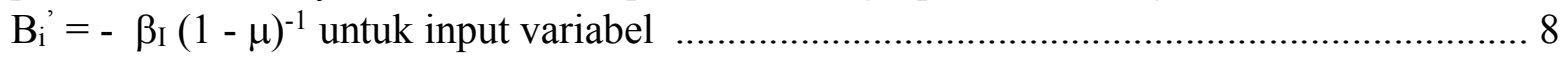

dimana :

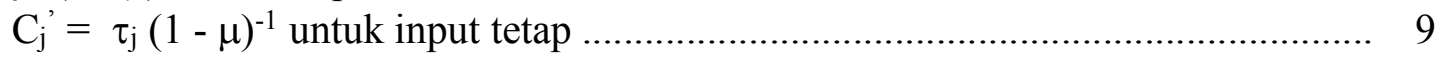

$\mu=\Sigma \beta_{\mathrm{I}}$, dan

$\beta_{\mathrm{I}}$ dan $\tau_{\mathrm{j}}$ diestimasi dari persamaan (8).

Elastistas produksi tidak langsung $\left(\mathrm{b}_{\mathrm{i}}{ }^{\prime}\right.$ dan $\left.\mathrm{c}_{\mathrm{j}}{ }^{\prime}\right)$ dan elastisitas produksi yang diestimasi secara langsung dari fungsi produksi persamaan (4) dilihat pada Tabel 5.

Tabel 5. MLE Fungsi Produksi dan Elastisitas Produksi diturunkan dari Fungsi Produksi

\begin{tabular}{llll}
\hline Variabel & Unit & MLE Estimasi & Indirect Estimasi \\
\hline Konstanta & $\mathrm{Kg}$ & 802,098 & \\
Pupuk & $\mathrm{Kg}$ & $0,212^{* *}(0,218)$ & 0,112 \\
Pestisida & $0,238^{* *}(0,187)$ & 0,109 \\
Tenaga Pemeliharaan & Hari & $0,188^{*}(0,043)$ & 0,142 \\
Tenaga Pemanenan & Hari & $0,159^{* *}(0,139)$ & 0,188 \\
Luas Lahan & $\mathrm{Ha}$ & $0,189^{* *}(0,156)$ & 0,197 \\
Modal & $\mathrm{Rp}$ & $0,174^{* *}(0,158)$ & 0,109 \\
\hline
\end{tabular}

Estimasi langsung $(1,159)$ dan tidak langsung $(0,857)$ yang menurunkan elastisitas produksi menerangkan bahwa decreasing return to scale tergambarkan. Elastisitas produksi yang diestimasi untuk lahan $(0,189)$ adalah konsisten dengan yang dilaporkan oleh Kikuchi dan Hayami (1998). Elastisitas produksi sedikit rendah untuk pestisida dibandingkan untuk pupuk. Hal ini bukanlah aneh karena petani sekarang menanam varietas unggul lokal yang respon terhadap pupuk, juga tahan terhadap beberapa pestisida.

\section{PENUTUP}

Elastisitas produksi usahatani jagung lahan kering diestimasi menggunakan analisis fungsi produksi untuk sampel petani di Kecamatan Kumpeh, Kabupaten Muaro Jambi, yang telah menerapkan teknologi budidaya yang baik. Diasumsikan dalam pendekatan ini yang diuji bahwa petani memaksimukkan short term produksi, dengan tersedianya teknologi dan sumber daya yang tetap. Analisis memperlihatkan bahwa petani sampel rata-ratanya memaksimumkan produksi dengan mempertimbangkan kondisi normal dari input variabel,

Analisis menerangkan juga bahwa petani jagung lahan kering didaerah penelitian respon terhadap perubahan penggunaan input dengan efisien. Penawaran output adalah respon terhadap produksi jagung. Pada permintaan input, banyak sensitif terhadap penggunaan tenaga kerja, tenaga pemeliharaan/ pemanenan. Elastisitas produksi yang diperoleh melengkapi bagian dari data base yang diperlukan intuk mengevaluasi implikasi kebijaksanaan penggunaan input alternatif dari persediaan jagung dan permintaan input. 


\section{DAFTAR PUSTAKA}

Aiginger, 2002 Farm-level Acreage Allocation under Risk. Paper in American Agricutural Economics Association Annual Meeting, Long Beach. California USA. Pp. 1-26.

Anonim, 2016. Jambi dalam Angka. Badan Perencanaan dan Pembangunan Daerah Provinsi Jambi. Jambi

Badan Pusat Statistik (BPS). 2016. Statistik Provinsi Jambi. Jambi

Bakhshoodeh, M. dan Shajari, S. 2006. Adoption of New Seed Varietas Under Production Risk: An Application to Rice in Iran. The International Assoc. of Agr. Economists Conference, Gold Coast, Australia. Pp. 1-11.

Dinas Pertanian Tanaman Pangan Provinsi Jambi, 2016. Laporan Tahunan Provinsi Jambi.

Edison, 2011. Analisis Respon Penawaran Padi dalam Kondisi Berisiko di Provinsi Jambi. Disertasi. Pascasarjana Universitas Sriwijaya, Palembang.

Guyomard, H.; Baudry, M. dan Carpenter, A. 2003. Estimating Crop Supply Response in the Presence of Farm Programmes: Application to the CAP. European Review of Agricultural Economics 23:401-420.

Houck, P dan Ryan, J. 2003 Weather Risk and The Off-Farm Labor Supply of Agricultural Households in India. Paper in International Association of Agricultural Economists Conference, Gold Coast. Australia. Pp. 1-15.

Judge, 2004. Fndamental of Econometrics: Theory and Applications. University of Wisconsin Press. U.S.A.

Keeney, R. dan Hertel T.W. 2008. Yield Response to Prices: Implications for Policy Modelling. Working Paper Dept. of Agricultural Economics Purdue University. Pp. 136.

Kikuchi, M and Hayami, Y. 1998. Inducement of Institutional Innovations in an Agrarian Community, Economic Dev. And Cultural Change 29(1) : 21-36.

Lau, L.J. dan Yotopoulus, P.A. 1972. Profit, Supply, and Factor Demand Functions. American Journal of Agricultural Economics,. 54:11-18.

Lu, W.; Xi, A.; dan Ye, J. 2006. Modelling Risk Behavior of Agricultural Production in Chinese Small Households. Poster paper prepared for presentation at International Association of Agricultural Economists Conference, Gold Coast Australia.

Pitt, M.M. 1999. Farm Level Fertilizer Demand in Java : A Meta Production Function Approach. American Journal of Agr. Economics 65:502-508

Pope, R.D. dan Kramer, R.A. 1999. Production Uncercainty and Factor Demands for the Competitive Firm, Southern Economics Journal, 46:489-501 